\title{
LVI. On a mode of deducing the equation of Fresnel's Wave
}

\author{
Sir William Rowan Hamilton LL.D. P.R.I.A.
}

To cite this article: Sir William Rowan Hamilton LL.D. P.R.I.A. (1841) LVI. On a mode of deducing the equation of Fresnel's Wave, Philosophical Magazine Series 3, 19:125, 381-383, DOI: $10.1080 / 14786444108650443$

To link to this article: http://dx.doi.org/10.1080/14786444108650443

册 Published online: 01 Jun 2009.

Submit your article to this journal $\widetilde{\pi}$

Џ Article views: 3

Q View related articles $₫$ 
according to descending powers of $\cos \theta$ (where $n$ is a positive integer), it seems extremely doubtful whether anything would be gained by its introduction in an elementary work; the method given in the ordinary trentises on trigonometry depending on the logarithmic series, is on every account preferable.

In the same article in your Number for August there is given a proof that $\Delta^{n} x^{m}=0$ when $m<n$.

If the author of it will only turn to art. 885 in Lacroix, I am convinced that he will regret having offered his new demonstration.

Trinity College, Cambridge, Aug. 24, 1841 .

J. E.

LVI. On a Mode of deducing the Equation of Fresnel's Wave. By Sir William Rowan Hamilton, LL.D., P.R.I.A., Member of several Scientific Societies at Home and Abroad, Professor of Astronomy in the University of Dublin, and Royal Astronomer of Ireland*.

THE following does not pretend to be the best, but merely to be one way, of deducing the known equation of Fresnel's wave, from a known geometrical construction. It requires only the first principles of the application of algebra to the geometry of three dimensions, and does not introduce any of the geometrical properties of the auxiliary ellipsoid employed, except those which are immediately suggested by the equation of that ellipsoid. It has, therefore, in the algebraical point of view, a certain degree of directness, although it might be rendered easier and shorter by borrowing more largely from geometry.

1. The known construction referred to is thus enunciated by Sir John Herschel, in his Treatise on Light, Encyclopcedia Metropolitana, article 1017. "M. Fresnel gives the following simple construction for the curve surface bounding the wave in the case of unequal axes, which establishes an immediate relation between the length and direction of its radii. Conceive an ellipsoid having the same semiaxes $a, b$, $c$; and having cut it by any diametral plane, draw perpendicular to this plane from the centre two lines, one equal to the greatest, and the other to the least radius vector of the section. The loci of the extremities of these perpendiculars will be the surfaces of the ordinary and extraordinary waves."

2. The coordinates of the wave being $x y z$, and those of the ellipsoid X Y Z, we have the six equations,

* Communicated by the Author. 


$$
\begin{gathered}
\frac{\mathrm{X}^{2}}{a^{2}}+\frac{\mathrm{Y}^{2}}{b^{2}}+\frac{\mathrm{Z}^{2}}{c^{2}}=1, . . \\
\mathrm{X} d \mathrm{X} \\
a^{2}+\frac{\mathrm{Y} d \mathrm{Y}}{b^{2}}+\frac{\mathrm{Z} d \mathrm{Z}}{c^{2}}=0, . \\
x \mathrm{X}+y \mathrm{Y}+z \mathrm{Z}=0, . . \\
x d \mathrm{X}+y d \mathrm{Y}+z d \mathrm{Z}=0, . . \\
\mathrm{X} d \mathrm{X}+\mathrm{Y} d \mathrm{Y}+\mathrm{Z} d \mathrm{Z}=0, \\
x^{8}+y^{2}+z^{2}=\mathrm{X}^{2}+\mathrm{Y}^{2}+\mathrm{Z}^{2} ; . .
\end{gathered}
$$

between which we are to eliminate $X, Y, Z$, and the ratios of their differentials.

3. The equations (1.) and (2.) are satisfied by assuming

$\mathrm{X}=a \sin \theta \cos \phi, \mathrm{Y}=b \sin \theta \sin \phi, \mathrm{Z}=c \cos \theta ;$ and then the equation (3.) gives

$$
\tan \theta=\frac{-c z}{a x \cos \phi+b y \sin \phi} ; . . . .
$$

while the comparison of the two values of $\tan \theta \frac{d \phi}{d \theta}$, deduced from (4.) and (5.), gives

$\frac{a x \cos \phi+b y \sin \phi-c z \tan \theta}{a x \sin \phi-b y \cos \phi}=\frac{a^{2} \cos \phi^{2}+b^{2} \sin \phi^{2}-c^{2}}{\left(a^{2}-b^{2}\right) \sin \phi \cos \phi}$;

and the equation (6.) becomes

$\left(x^{2}+y^{2}+z^{2}\right)\left(\mathrm{I}+\tan \theta^{2}\right)=\left(a^{2} \cos \phi^{2}+b^{2} \sin \phi^{2}\right) \tan \theta^{2}+c^{2}$. (10.) It remains therefore to eliminate $\theta$ and $\phi$ between the three equations (8.) (9.) (10.).

4. Substituting for $\tan \theta$, in (9.) and (10.), its value given by (8.), we easily obtain

$A \tan \phi+B \operatorname{cotan} \phi=C$; . . . . . if we put for abridgement

$$
\mathrm{A}^{\prime} \tan \phi+\mathrm{B}^{\prime} \operatorname{cotan} \phi=\mathrm{C}^{\prime}
$$

$$
\begin{aligned}
& \mathbf{A}=\left(c^{2}-b^{2}\right) a b x y ; \\
& \mathbf{B}=\left(a^{2}-c^{2}\right) a b x y \\
& \mathbf{C}=\left(b^{2}-c^{2}\right) a^{2} x^{2}+\left(c^{2}-a^{2}\right) b^{2} y^{2}+\left(b^{2}-a^{2}\right) c^{2} z^{2} ; \\
& \quad r^{2}=x^{2}+y^{2}+z^{2} ; \\
& \mathbf{A}^{\prime}=r^{2}\left(b^{2} y^{2}+c^{2} z^{2}\right)-c^{2} b^{2}\left(y^{2}+z^{2}\right) ; \\
& \mathbf{B}^{\prime}=r^{2}\left(a^{2} x^{2}+c^{2} z^{2}\right)-c^{2} a^{2}\left(x^{2}+z^{2}\right) ; \\
& \mathbf{C}^{\prime}=-2\left(r^{2}-c^{2}\right) a b x y .
\end{aligned}
$$

And eliminating $\phi$ between the equations (I.) and (II.), we find:

$\left(\mathrm{A} \mathrm{B}^{\prime}-\mathrm{A}^{\prime} \mathrm{B}\right)^{2}+\left(\mathbf{A} \mathrm{C}^{\prime}-\mathrm{A}^{\prime} \mathrm{C}\right)\left(\mathrm{B} \mathrm{C}^{\prime}-\mathrm{B}^{\prime} \mathrm{C}\right)=0$; (III.) a form for the equation of the wave, which we have now only to develope and depress. 
5. Expanding it first under the form

$$
\mathbf{W}_{8}+\mathbf{W}_{10}+\mathbf{W}_{12}=0 \text {, }
$$

in which $W_{8}, W_{10}, W_{12}$ are, respectively, homogeneous functions of $x, y, z$, of the 8th, 10 th, and 12 th dimensions, we soon discover that these three functions have a common factor, of the 8th dimension, namely, $c^{2} z^{2} r^{2} \mathbf{R}^{2}$, in which

$$
\mathrm{R}^{2}=\mathrm{C}^{2}+4 a^{2} b^{2}\left(c^{2}-a^{2}\right)\left(c^{2}-b^{2}\right) x^{2} y^{2},
$$

$\mathrm{C}$ having the same meaning as in (I.), so that

$$
\mathbf{R}^{2}>0 \text {, if } c^{2}>b^{2}>a^{2} \text {, or if } c^{2}<b^{2}<a^{2} \text {, }
$$

conditions which we may suppose to be satisfied. And rejecting, as evidently foreign to the question, this common factor $c^{2} \approx^{2} r^{2} R^{2}$, the known equation of the wave results, under the form

in which

$$
\begin{gathered}
u_{0}+u_{2}+u_{4}=0, \ldots \ldots \ldots \\
u_{0}=a^{2} b^{2} c^{2}
\end{gathered}
$$$$
u_{2}=\left(x^{2}+y^{2}+z^{2}\right)\left(a^{2} x^{2}+b^{2} y^{2}+c^{2} z^{2}\right) \text {. }
$$

6. The foregoing investigation is taken from a manuscript Report which I had the honour of drawing up in July 1890, when, in conjunction with the late and present Provosts of Trinity College, Dublin, I was appointed to examine the first communication of Professor MacCullagh to the Royal Irish Academy, since published in the second part of the sixteenth volume of the Transactions of that body. A far more concise and elegant deduction of the same known equation of the wave from the same geometrical construction, depending, however, a little more on the geometrical properties of the ellipsoid, has since been communicated by Professor MacCullagh himself, and is published in the second part of the seventeenth volume of the Transactions of the same Academy. Others have published other demonstrations.

My own mode of deducing the equation of the wave from the principles of Fresnel, without any reference to the ellipsoid above referred to, may be seen in the "Third Supplement' to my 'Theory of Systems of Rays contained in the first part of the last-mentioned volume.

Observatory of Trinity College, Dublin, October 13, 1841.

P.S. Since writing out and sending off the foregoing paper, I have had opportunity to refer to Fresnel's own deduction of the'same equation of his wave from the same geometrical construction, entitled "Calcul très simple qui conduit de l'équation d'un ellipsoide à celle de la surface des ondes." (Mém. de l'Acad. des Sci. de l'Inst. Royale de France, tom. vii., page 137.) It is much simpler than mine, and nearly coincident with that of Professor MacCullagh, but seems to have been overlooked by both of us, 